\title{
Seismicity Parameters Analysis In Space-Time Distribution For Northeast India.
}

Auchitya Kumar Pandey ( $\square$ auchityapandey90@gmail.com )

Kumaun University

\section{Research Article}

Keywords: Earthquake Catalogue, Maximum-likelihood Method, Northeast India, Seismicity Parameters, Spatial Variation, Return Period

Posted Date: May 18th, 2021

DOI: https://doi.org/10.21203/rs.3.rs-421057/v1

License: (9) This work is licensed under a Creative Commons Attribution 4.0 International License. Read Full License 


\section{Abstract}

A complete homogeneous earthquake catalogue is prepared to estimate seismicity parameters and their spatial-temporal variation in nine seismogenic source zones for Northeast India. The value of seismicity parameters like $a$-value, $b$-value, and $M_{C}$ value i.e., 7.37, 0.93( \pm 0.013$)$, and 4.6, respectively have been estimated from the frequency-magnitude distribution. Moreover, the maximum-likelihood method has been utilized to map the spatial variation of the above parameters. The spatial variation of low $b$-values is dominant in the Indo-Burman Range, the Main Boundary Thrust, and the vicinity of the Sagaing fault. High seismic activity rate has been obtained in the Indo-Burman range as observed from spatial variation of a-value parameter. Furthermore, the return periods and the annual probability of an earthquake have been calculated for each zone. The results of this seismicity parameter provide useful information about the hazard level of a particular zone and further helps in preparing the hazard map of Northeast India.

\section{Introduction}

Natural hazards such as earthquake, tsunami, and flood are a serious threat to the people living. The earthquake is considered as one of them a destructive natural phenomenon in the world due to which several damages to man-made buildings, loss of human life, and environmental affect. The occurrence of moderate to large magnitude earthquakes makes this study region as high seismically active of the Indian sub-continent. In the past 120 years, several low to high magnitude earthquakes $\left(M_{W} \geq 3.0\right.$ to above 7.0) have occurred in Northeast India. But this region has been experienced by two devastating earthquakes above $M_{W} \geq 7.0$ such as 15 th August, 1950 Assam earthquake $\left(M_{W} \geq 8.6\right)$ and 12th June, 1897 Shillong earthquake $\left(M_{W} \geq 8.1\right)$ (Oldham 1899; (Bilham and England, 2001; Bilham 2004; Kayal et al., 2012, Pandey et al., 2017; 2019) as depicted in Figure. 1. Thus, the major devastating earthquakes $\left(M_{W} \geq 6.5\right)$ that occurred since 1897 in and around Northeast India and their description are listed in Table-1 (Pandey et al., 2017). The Indian Plate and the Eurasian Plate convergence and continentcontinent collision in the north direction and subduction of the Indian plate beneath the Burmese plate in the east direction is the prime reason for the occurrence of low to high magnitude earthquakes (Bilham and England, 2001; Angelier and Baruah, 2009; Kayal et al., 2010, 2012). Resulting, the seismicity level of this study region has been increased in recent decades and vulnerable to hazard in this region. To minimize the hazard level of this study region numerous studies have been done by several authors such as (Angelier and Baruah, 2009; Kayal et al., 2006; Baruah et al., 2013; Bora et al., 2013) based on seismicity and seismotectonic analysis. Thus, the seismicity parameters study can help to reveal some aspects to minimize the seismic activity rate and vulnerability in any complex study region (Jafari, 2013). The seismicity parameters investigation has been done in the past by several researchers such as (Kolathayar et al., 2012; Nayak and Sitaram, 2019; Gautam et al., 2018) in and around Northeast India. These studies were based on different techniques by using the instrumental or both historical and instrumental earthquake catalogue (Nayak and Sitaram, 2019). Also, the seismicity parameters analysis in terms of spatial-temporal distribution has been done by several authors such as Shankar and Sharma, (2012); El-Quliti, (2016) for the different tectonic settings of the world in the recent past. 
Table-1 List of major destructive earthquakes $\left(M_{W} \geq 6.5\right)$ since 1897 in and around Northeast India. 


\begin{tabular}{|c|c|c|c|c|c|c|}
\hline $\begin{array}{l}\text { S. } \\
\text { No. }\end{array}$ & Place & Date & Latitude $(\mathbb{\nabla N})$ & Longitude(区E) & $\begin{array}{l}\text { Magnitude } \\
\left(M_{W}\right)\end{array}$ & Description \\
\hline \multirow[t]{2}{*}{1} & $\begin{array}{l}\text { Chachar } \\
\text { Earthquake }\end{array}$ & $\begin{array}{l}10 \\
\text { January, } \\
1969\end{array}$ & 24.66 & 92.85 & 7.3 & $\begin{array}{l}\text { Damaging } \\
\text { in the region } \\
\text { from Dhubri } \\
\text { to the east } \\
\text { of }\end{array}$ \\
\hline & & & & & & $\begin{array}{l}\text { Imphal and } \\
\text { between } \\
\text { Nowgong } \\
\text { and Silchar }\end{array}$ \\
\hline \multirow[t]{3}{*}{2} & $\begin{array}{l}\text { Shillong } \\
\text { Earthquake }\end{array}$ & $\begin{array}{l}12 \text { June, } \\
1897\end{array}$ & 26.00 & 91.00 & 8.1 & $\begin{array}{l}\text { Damaged } \\
\text { every stone } \\
\text { house, } 13 \\
\text { deaths. } \\
\text { Damages }\end{array}$ \\
\hline & & & & & & $\begin{array}{l}\text { were } \\
\text { observed in } \\
\text { Umananda } \\
\text { Island } \\
\text { temple and }\end{array}$ \\
\hline & & & & & & railway lines \\
\hline \multirow[t]{2}{*}{3} & $\begin{array}{l}\text { Dhubri } \\
\text { Earthquake }\end{array}$ & $\begin{array}{l}03 \text { July, } \\
1930\end{array}$ & 25.93 & 90.18 & 7.1 & $\begin{array}{l}\text { In Dhubri } \\
\text { area, } \\
\text { damages of } \\
\text { the } \\
\text { buildings. } \\
\text { No }\end{array}$ \\
\hline & & & & & & Fatalities \\
\hline \multirow[t]{2}{*}{4} & $\begin{array}{l}\text { Assam } \\
\text { Earthquake }\end{array}$ & $\begin{array}{l}29 \text { July, } \\
1947\end{array}$ & 28.50 & 94.00 & 7.3 & $\begin{array}{l}\text { Cracks in } \\
\text { walls at } \\
\text { Guwahati } \\
\text { area. Failure } \\
\text { of }\end{array}$ \\
\hline & & & & & & $\begin{array}{l}\text { electricity } \\
\text { observed }\end{array}$ \\
\hline 5 & $\begin{array}{l}\text { Assam } \\
\text { Earthquake }\end{array}$ & $\begin{array}{l}15 \text { August, } \\
1950\end{array}$ & 26.6 & 96.5 & 8.6 & $\begin{array}{l}1500 \text { people } \\
\text { were killed } \\
\text { and the } \\
\text { drainage } \\
\text { affected }\end{array}$ \\
\hline 6 & $\begin{array}{l}\text { Near Moirang, } \\
\text { Southern } \\
\text { Manipur }\end{array}$ & $\begin{array}{l}01 \text { July, } \\
1957\end{array}$ & 24.40 & 93.80 & 7.2 & $\begin{array}{l}10,000 \\
\text { people died }\end{array}$ \\
\hline
\end{tabular}




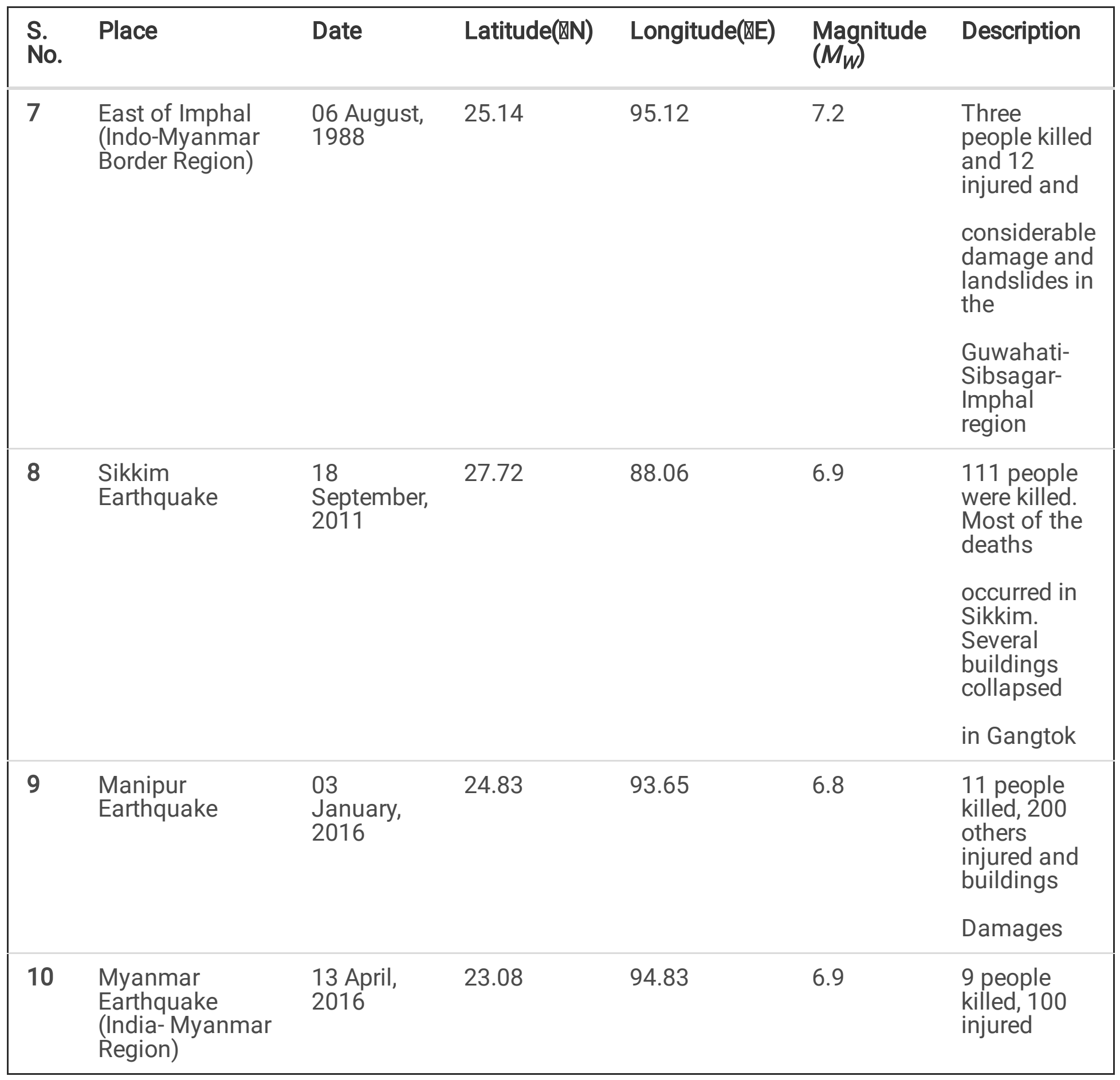

The prime object of the present study is the investigation of seismicity parameters such as a-value, $b$ value, $M_{C}$ value, and their spatial-temporal distribution in nine seismogenic source zones using the updated earthquake catalogue (1976-2020) for the entire Northeast India. A comprehensive and complete homogeneous earthquake catalogue is required for the study of seismicity parameters. A complete homogeneous earthquake catalogue $\left(M_{W} \geq 3.0\right)$ has been prepared by using the datasets of the different agency during the period from 1st January, 1976 to 31st June, 2020. To remove the dependent variables (i.e., foreshocks and aftershocks) from the entire earthquake catalogue, a decluster technique proposed by Uhrhammer, (1986) have been utilized. The zonation map of Angelier and Baruah, (2009) has been adopted to prepare the seismotectonic map (Figure. 1) of the study region (Pandey et al., 
2019). The Maximum-likelihood method (MLM) has been employed to estimate the seismicity parameters and their spatial variation by using decluster catalogue. The temporal variations of earthquakes have been shown by using the Gutenberg-Richter relationship. Also, the Return periods and annual probability of different magnitudes of earthquakes occurrence have been estimated based on these seismicity parameters values for each zone in this study region.

\section{Seismotectonic Setting Of Ne India}

Northeast India has a complex tectonic domain in the world. This study region is a high seismically active region that encompasses the latitude and longitude as $21^{\circ} \mathrm{N}-30^{\circ} \mathrm{N}$ and $81^{\circ} \mathrm{E}-98^{\circ} \mathrm{E}$. Northeast India falls into the highest seismic active zone, i.e., Zone V, according to the seismic zonation map of India (BIS, 2002; Pandey et al., 2017). The seismicity of Northeast India is significantly very high because of low to high magnitude earthquakes that occurred, causing loss of human life and destroyed buildings (Yadav et al., 2009). In the last 120 years, several earthquakes above $M_{W} \geq 7.0$ have been experienced in this region, wherein two devastating earthquakes i.e., Shillong earthquake on 12th June, 1897 and Assam earthquake on 15th August, 1950 both above $M_{W} \geq 8.0$ majorly affected this region (Baruah et al., 2012; Pandey et al., 2017). The continent-continent collision and convergence of the Indian Plate with the Eurasian Plate and Subduction of the Indian Plate underneath the Burmese Plate towards north and east direction is the prime cause to increases the seismicity in this study region. Also, this region is more complex due to the upliftment of the Shillong plateau by the effect of the Dauki fault and the Brahmaputra basin (Kayal, 2012). Such, pop-structure of the Shillong plateau is defined by Bilham and England, (2001) based on geodetic and GPS data interpretation which is bounded by reverse fault.

Based on the active tectonic structures, focal mechanism of earthquakes, and seismicity level this study region has been categorized into four seismogenic source zones, i.e., the Eastern Syntaxis (Zone-I), the Arakan-Yoma subduction belt (Zone-II), the Shillong Plateau (Zone-III), and the Main Central Thrust (MCT) and the Main Boundary Thrust (MBT) of the Himalayan Thrusts Zone (Zone-IV) (Yadav et al., 2009; Pandey et al., 2017, 2019). Furthermore, this region is also sub-divided into nine seismogenic source zones based on seismicity, geological features, and orientation of the faults, (Angelier et al., 2009; Pandey et al., 2019). There are several major faults present such as Sagaing fault, Mat fault, Sylhet fault Po-chu fault, Kopili fault, and Dauki fault. At present time, some faults are very active and accountable to increases the seismicity rate due to several low to high magnitude earthquake occurrences in Northeast India. A seismotectonic map of Northeast India is depicted in Figure-1 and red stars represent the large earthquakes that occurred in this study region.

\section{Earthquake Catalogue}

The comprehensive and complete homogeneous earthquake catalogue is an essential input to quantify the seismicity parameters for any tectonic setting. A homogeneous earthquake catalogue $\left(M_{W} \geq 3.0\right)$ has been prepared covering the period from 1st January, 1976 to 31st June, 2020 for the study region. The earthquake catalogue is compiled from various agencies such as the International Seismological Centre 
(ISC) and Global Centroid Moment Tensor (GCMT) to estimate the seismicity parameters and their spatial-temporal variation for this study region. These catalogues contain the different types of magnitude scales i.e., $M_{L}, m_{b}$, and $M_{S}$ have been converted into single moment magnitude scales $\left(M_{W}\right)$ by adaptation of the regression equation of Pandey et al., (2017) for Northeast India.

The earthquake catalogue should be entirely independent of foreshocks and aftershocks for accurate assessment of seismicity parameters. The homogeneous earthquake catalogue is encompassing the foreshocks, mainshocks, and aftershocks from various sources and it may be repeated which have to be filtered (Kolathayar et al., 2012). The earthquake catalogue has been performed in the ZMAP software (Weimer, 2001) by utilizing a decluster technique developed by Uhrhammer, (1986) to filter the dependent events (i.e., foreshocks, aftershocks) and repeated earthquake events from the mainshocks. Also, the magnitude of completeness which is defined as the minimum magnitude at which $100 \%$ of the earthquake has been detected in space-time volume i.e., the seismic network provides the complete detection of an event without missing a single event has been examined for this study region (Rydelek and Sacks, 1989; Schorlemmer and Woessner, 2008; Woessner and Wiemer, 2005).

\section{Methodology}

\section{b-value-}

The basic seismological parameter is the $b$-value which ensemble of earthquakes in the frequencymagnitude relation for any tectonic setting (Singh, 2016). A well-document simplest relationship has been established by Gutenberg and Richter, (1944) which shows the frequency of earthquakes of occurrence of earthquakes as a function of magnitude: (Srivastava, 2014; Roy et al., 2010).

$\log 10 N(M)=a-b M$ equ $(1)$

where $\mathrm{N}$ is the number of earthquakes in a group having a magnitude larger than $\mathrm{M}$. The parameter a and $b$ are positive real constant and these coefficients change values are depending on the various tectonic feature of each earthquake source zone. The parameter "a" is described as seismicity activity which depends on the size of the area, observation period length, largest seismic magnitude, and the stress level of the area (Allen, 1986). The parameter " $b$ " is the slope of the log-linear relation and it is known as the $b$ value (Srivastava, 2014). Normally, the $b$-value is 1.0 on a global scale, but the range of $b$-value is lying in between 0.5 to 1.5 which depends on the tectonic settings of the seismically active region (Singh, 2016; Pacheco et al., 1992; Wiemer and Wyss, 1997; Singh et al., 2008; Singh and Chadha, 2010). The $b$-value can be used for the study of seismicity, seismotectonic, and seismic hazard assessment for any geological setting. The $b$-value can be computed by using two methods such as least-square fit method and the Maximum-likelihood method for any tectonic setting. In the least square fit method, the log values of the cumulative number of earthquakes $(\mathrm{N})$ are plotted with a magnitude sequence. The $b$-value is estimated from the slope of the least square fit line, the log-linear relation between $\mathrm{N}$ and $\mathrm{M}$. However, the Maximum-likelihood method (MLM) (Aki, 1965) is the most robust and accepted method utilized to 
estimate the $b$-value for any study region. Thus, the Maximum-likelihood method based on theoretical consideration has been utilized to compute the $b$-value in $0.5^{\circ} \times 0.5^{\circ}$ grid interval for this study region. The $b$-value parameter estimates from the given formula as:

$b=\log _{10}(e) / m_{\text {mean }}-(M c-(\Delta m / 2))$ equ $(2)$

where $\mathrm{m}_{\text {mean }}$ is the mean magnitude of the sample, $M c$ is the magnitude of completeness and $\Delta m$ is the magnitude bin size.

\section{Return Period and Annual Probability-}

The return period and annual probability of $M_{W}=3.0$ earthquake in nine seismogenic source zones are estimated by utilizing the value of seismicity parameters such as "a" and " $b$ ". Return period or Recurrence interval is the average interval of time within which an earthquake of specified magnitude is probable to be equaled or surpassed at least once (El-Quliti, 2016). Percentage probability is estimated by dividing 1 by the Return period or Recurrence interval and multiplying by 100 (EI-Quliti, 2016). Thus, the return period and annual probability Percentage has been estimated by equation 1 and 2 respectively as given below:

Return Period $\left(T_{R}\right)=(n+1) / m$ equ $(3)$

Annual Probability Percentage $(P(M))=100 . m /(n+1)$ equ (4)

Where $\mathrm{m}$ is event ranking and is the number of events in the period of record.

\section{Result And Discussion}

The seismicity parameters and their spatial-temporal distribution are investigated in nine seismogenic source zone by using the updated homogeneous earthquake catalogue from the period of 1976-2020 for Northeast India. These seismicity parameters are providing the information to identify the high seismically active zone in the near prospect of this study region. Thus, the spatial distribution of $b$-value has been estimated by using the Maximum-likelihood method which varies from 0.6 to 1.52 in this study region as depicted in Figure. 2. High $b$-value is exhibited by the distribution of low stress which indicates the creeping of the faults in the southern part of the Indo-Burman range (Mizo folds and Chin Hills) and also in the Sikkim region due to the occurrence of low magnitude earthquakes along the fault in recent past. However, the low $b$-value is present in most of the Indo-Burman range and the surrounding region of the Sagaing fault in the study region. These low $b$-values are associated with the high magnitude of earthquakes occurrence, high crustal stress build-up in the locking segments of the fault, and heterogeneity of material (Gautam et al., 2018, Pandey et al., 2019). Furthermore, the low b-value is primarily due to the large earthquake occurrences in the region as suggested by Nuannin et al., (2005). The moderate $b$-value is found in the rest of the study region. From Figure. 3 , it has been found that most of the Indo-Burman range and other areas exhibited a less standard $b$-value (i.e., 0.01), which ensures less uncertainty in the estimation of $b$-value in this study region. The result of the $b$-value in the present study 
is well matching with the previously obtained by several authors such as Yadav et al., 2009; Thingbaijam et al., 2009; Pandey et al., 2017; Pandey et al., 2019; Nayak and Sitaram, 2019 for Northeast India. There are several reasons such as earthquake events time period, source, and methodology which associate the difference in the estimation of $b$-value (Nayak and Sitaram, 2019).

The spatial distribution of parameter "a-value" which describes the level of seismicity is computed like the parameter " $b$-value" for Northeast India. The estimated a-value varies from 3.13 to 8.73 for this study region as shown in Figure. 4. From this Figure, high a-value is observed in the southern part of the IndoBurman range in the range of 6.5 to 8.73 . The high hazard level in terms of seismicity has been observed by estimation of a-value due to the occurrence of large earthquakes in the study region. Most of the study regions such as the northern part of the Indo-Burman range, the Main Boundary Thrust, and the vicinity of the Sagaing fault is showing a low a-value in the range of 3.13 to 4.0 as depicted in Figure. 4. Also, some areas such as in and around the Sikkim area and Chin Hills, Naga Disang Thrust) shows the moderate avalues which varies from 4.0 to 6.5. Previously, a-value has been estimated for the Indo-Burman range and observed that a-value lies in the range of 2.05 to 4.06 (Gautam et al., 2018). Kolathayar et al., (2012) have been estimated the a-value for the entire Himalayan region and observed that the low a-value is an exhibit in the eastern Himalaya. Moreover, the low and high a-value has been calculated by several researchers such as (Nayak and Sitaram, 2019; Thingbaijam et al., 2008; Yadav et al., 2009; Pandey et al., 2019) for this study region and its good matches with the present study.

The magnitude of completeness $\left(M_{C}\right)$ has been estimated for Northeast India and it is varying from 4.0 to 4.8 as shown in Figure. 5. The low $M_{C}$ value has been observed in the range of 4.0 to 4.2 in the area of northern and southern Indo-Burman range, Main Boundary Thrust, and also in and around the Sikkim (Figure. 5). The southern part of the Indo-Burman range and Chin Hills area represent the high $M_{C}$ value of the range 4.7-4.8 in this study region. In addition, the moderate $M_{C}$ value is obtained which varies from 4.3-4.5 in between the area of the southern part of the Indo-Burman range and volcanic line and Sikkim area. Gautam et al., (2018) have been estimated the $M_{C}$ value which varies from 2.0 to 3.5 in the Indo-Burman range to shows the spatial-temporal distribution of seismicity parameter for Northeast India. It has been observed that low $M_{C}$ values are present in the range 2.0 to 2.7 in Naga and Disang Thrust and the northern part of Sagaing fault of the study region. Also, high $M_{C}$ values are observed by Gautam et al., (2018) in the area of the southern part of the Indo-Burman range, Chin Hills, and Mizo fold which well-matches with the present study. The spatial distribution of $M_{C}$ value has been calculated by Nayak and Sitaram, (2019) for the entire Himalayan region and observed that the low $M_{C}$ value is present in Northeast India.

Further, the frequency-magnitude distribution plot has been computed by using ZMAP software for Northeast India as shown in Figure. 6. From Figure. 6, the seismicity parameters values have been obtained such as a-value, $b$-value, and $M_{C}$ value are $7.37,0.93( \pm 0.013)$, and 4.6 respectively. Also, the seismicity parameters for nine seismogenic source zone have been estimated in frequency-magnitude distribution as listed in Table-2. Recently, the seismicity parameter values have been estimated by several 
authors such as Nayak and Sitaram, (2019); Thingbaijam et al., (2008); Pandey et al., (2019) for this study region. Yadav et al., (2009) has been computed the value of $a, b$, and $M_{C}$ as $7.94,0.93( \pm 0.023)$, and 4.6 respectively for the same study region, which shows a good correlation with the present result of this study region. Also, seismicity parameters value has been estimated for this study region and it was found to be the value of $a, b$, and $M_{C}$ as $7.50,0.95$ ( \pm 0.023 ), and 4.6 respectively (Pandey et al., 2017).

Finally, it has been concluded that the obtained values (discussed above) from the estimated seismicity parameters for this study region indicating that the Northeast region is currently high seismically active region, and some areas are reflected as most hazardous. Further, the seismicity parameters values are estimated based on the frequency-magnitude distribution for each zone as listed in Table-2. Resulting from this, low and high $b$-values are present in Zone-2 and Zone-7 along with $M_{C}$ values such as 3.5 and 4.8 respectively. Also, the low and high seismicity activity rate values are present in Zone- 2 and Zone-1 respectively.

Table-2 List of seismicity parameters values is estimated by FMD for nine seismogenic source zone of Northeast India.

\begin{tabular}{|lllllll|}
\hline S. No. & Seismic Zones & No. of Earthquakes & $\mathbf{M}_{\max }$ & $\boldsymbol{M}_{\boldsymbol{C}}$ & a-value & $\boldsymbol{b}$-value \\
\hline 1. & Zone 1 & 664 & 6.9 & 4.7 & 7.31 & $1.05( \pm 0.06)$ \\
\hline 2. & Zone 2 & 746 & 6.1 & 3.5 & 4.21 & $0.45( \pm 0.01)$ \\
\hline 3. & Zone 3 & 286 & 6.3 & 4.6 & 5.90 & $0.84( \pm 0.05)$ \\
\hline 4. & Zone 4 & 522 & 6.1 & 4.6 & 6.78 & $0.95( \pm 0.05)$ \\
\hline 5. & Zone 5 & 621 & 5.9 & 3.4 & 4.24 & $0.49( \pm 0.02)$ \\
\hline 6. & Zone 6 & 947 & 6.1 & 3.2 & 4.27 & $0.48( \pm 0.01)$ \\
\hline 7. & Zone 7 & 1459 & 6.9 & 4.8 & 8.12 & $1.17( \pm 0.03)$ \\
\hline 8. & Zone 8 & 1492 & 7.2 & 4.8 & 6.42 & $0.85( \pm 0.03)$ \\
\hline 9. & Zone 9 & 575 & 6.9 & 4.6 & 6.66 & $0.93( \pm 0.43)$ \\
\hline
\end{tabular}

The return period or recurrence interval $(\mathrm{R})$ and annual probability of occurrence of the different magnitude of the earthquake are calculated for each zone and it dramatically varies from one to another zone in the study region. The return period and annual probability of future earthquakes for $40 \mathrm{yrs}$ have been shown in Figure. 7 and Figure. 8. Also, the return period of different magnitude ( $M=4.0, M=5.0$ and $M=6.0$ ) respectively, for 40 yrs has been estimated as listed in Table-2. From Table-2, it has been observed that low return period values are present in Zone-7, Zone-7, and Zone-8 while high return period values are present in Zone-3, Zone-5, and Zone-3. However, Zone- 5 has never experienced an earthquake of $M=6.0$ or above magnitude in the $40 \mathrm{yrs}$ past. Thus, a low value of return period for different magnitude $(M=4.0$ and $M=5.0)$, indicating the Zone-7 is the high seismically active zone of Northeast India. Recently, the return period has been estimated for Northeast India by Nayak and Sitaram, (2019) 
and observed that a high return period was present for a magnitude of $M=7.0$ in this study region. Also, suggested that this study region has never experienced a large earthquake above $M=8.0$ in the past 50 year. Further, annual probability percentage of different magnitude $(M=4.0, M=5.0$ and $M=6.0)$ has been computed for 40 yrs by using equ (2) as shown in Table-2. Resulting from this, a low probability of occurrence of future earthquakes for different magnitudes $(M=4.0, M=5.0$, and $M=6.0)$ has been observed in the Zone-7, Zone-7, and Zone-8. However, Zone-7, Zone-5, and Zone-6 are exhibiting a high probability of occurrence of future earthquakes for different magnitudes $(M=4.0, M=5.0$, and $M=6.0)$ in Northeast India. The probability of occurrence of moderate to a large earthquake in $40 \mathrm{yrs}$ time period for the rest of the zones is $50 \%$ or less than $50 \%$. This analysis is indicating the probability of occurrence of low to high magnitude earthquake in Zone-7 i.e., the southern part of the Indo-Burman range and the vicinity of this area. Nayak and Sitaram, (2019) have been observed that this study region has been experienced a different magnitude of earthquake $M=6.0$ and $M=7.0$ in both $50 \mathrm{yrs}$ and $100 \mathrm{yrs}$. The probability of earthquake occurrence is high for magnitude $(M=6.0$ and $M=7.0)$, but for magnitude, $M=$ 8.0, the probability of earthquake occurrence is less than $50 \%$. Also, suggested that probability of occurrence of small to moderate magnitude earthquake in this study region.

Table-3 Illustrate the Return period or Recurrence interval and Annual probability for $40 \mathrm{yrs}$ in each seismogenic source zone of Northeast India.

\begin{tabular}{|llllllll|}
\hline S. No. & Seismic Zone & \multicolumn{3}{c}{ Return Period (Yrs) } & \multicolumn{4}{c|}{ Annual Probability (in 40 Yrs) } \\
\cline { 3 - 8 } & & $\mathbf{M = 4 . 0}$ & $\mathbf{M}=\mathbf{5 . 0}$ & $\mathbf{M}=\mathbf{6 . 0}$ & $\mathbf{M}=\mathbf{4 . 0}$ & $\mathbf{M}=\mathbf{5 . 0}$ & $\mathbf{M}=\mathbf{6 . 0}$ \\
\hline 1. & Zone 1 & 0.115 & 0.263 & 5.00 & 833.3 & 380.2 & 20 \\
\hline 2. & Zone 2 & 0.158 & 0.357 & 8.00 & 625 & 280.11 & 12.5 \\
\hline 3. & Zone 3 & 0.298 & 0.512 & 13.33 & 333 & 195.31 & 7.50 \\
\hline 4. & Zone 4 & 0.175 & 0.396 & 5.71 & 555.6 & 252.5 & 17.51 \\
\hline 5. & Zone 5 & 0.231 & 0.526 & - & 434.8 & 190.11 & - \\
\hline 6. & Zone 6 & 0.121 & 0.500 & 40.0 & 833.3 & 200 & 2.5 \\
\hline 7. & Zone 7 & 0.059 & 0.098 & 5.00 & 166 & 1020.4 & 20 \\
\hline 8. & Zone 8 & 0.064 & 0.131 & 2.00 & 1562.5 & 763.3 & 50 \\
\hline 9. & Zone 9 & 0.145 & 0.290 & 3.33 & 689.7 & 344.8 & 30.0 \\
\hline
\end{tabular}

\section{Conclusion}

The seismicity parameter analysis is helpful with regular updated seismological datasets from a seismological point of view. Seismicity parameters have been computed by using the available maximum information of seismology for this study region. Such kind of examination is support to understand the earthquake generation process of any tectonic setting. The reliability of results depends upon the input 
used like methodology information for the investigation of seismicity parameters for any study region. In the present article, different approaches have been utilized to estimate the seismicity parameters with the seismotectonic framework of the study region. This study region has been categorized into nine seismogenic source zone based on geological features, seismicity, and orientation of the faults in which the seismicity parameter has been estimated. The seismicity parameters such as $b$-value (0.6-1.52) with standard $b$-value $(0.01-0.38)$ and a-value $(3.13-8.73)$ are estimated by using the maximum likelihood method which indicating Northeast India is the most hazardous region. In this analysis, the $b$-value analysis providing information about the crustal stress level of the study region. Based on the $b$-value result, it has been observed that most areas of the Indo-Burman Range show high crustal stress and material heterogeneity due to the subduction of the Indian plate beneath the Burmese plate. Resulting, the probability of the occurrence of future large magnitude earthquakes is in Northeast India. It has been observed that Zone-7, 9 are low and Zone-8 is the high seismic active zone in this study region. Finally, it has been concluded that all zones are indicating the different types of hazard levels of the study region. Also, the return period and annual probability of occurrence of the earthquake have been estimated for 40 yrs by using the obtained value of seismicity parameters. The estimated seismicity level from one zone to another zone is very informatively and useful from both theoretical and practical points of view in this study. Resulting from this analysis, it has been noticed the seismicity level is high in most areas of Northeast India which indicating the vulnerability to hazard in the near prospect. The resultant hazard parameter, return periods, and the probability of occurrence may be utilized as quantitative measures of seismicity for any study region. In addition, this type of analysis will be helpful to prepare the probabilistic seismic hazard map in Northeast India.

\section{Declarations}

\section{Acknowledgment-}

The author is thankful to Professor Rajeev Upadhyay, Principal Investigator of the SNKH project, Department of Geology, Kumaun University, Nainital for providing the infrastructure facility to complete this research work and other necessary support.

\section{Declaration of Interest-}

In this work no financial interests were requirement and no personal relationship. So, all these things will not influence the present work in this article.

\section{References}

1. Aki, K., Maximum likelihood estimate of $b$ in the formula $\log N=a-b M$ and its confidence limits, Bull. Earthq. Res. Inst. Univ. Tokyo, 43, 237-239, 1965.

2. Allen, J. R. L., Earthquake magnitude-frequency, epicentral distance, and soft-sediment deformation in sedimentation basins, Sediment Geology, 46, 67-75, 1986. 
3. Angelier, J., S. Baruah, Seismotectonics in Northeast India: a stress analysis of focal mechanism solutions of earthquakes and its kinematic implications, Geophys. J. Int., 178, 303-326, 2009.

4. BIS IS 1893-2002, Indian Standard Criteria for Earthquake Resistant Design of Structures, Part 1 General Provision and Buildings. Bureau of Indian Standard, New Delhi, 2002.

5. Baruah, S., S. Baruah, J. R. Kayal, State of tectonic stress in Northeast India and adjoining South Asia region: an appraisal, Bull. Seismol. Soc. Am., 103(2A), 894-910, 2013.

6. Bilham, R., P. England, Plateau "pop-up" in the Great 1897 Assam earthquake, Nature, 410, 806-809, 2001.

7. Bilham, R., Earthquakes in India and the Himalaya: tectonics, geodesy and history, Ann Geophys, 47, 839-858, 2004.

8. Bora, D. K., S. Baruah, R. Biswas, N. K. Gogoi, Estimation of source parameters of local earthquakes originated in Shillong-Mikir plateau and its adjoining region of Northeastern India, Bull. Seismol. Soc. Am., 103(1), 437-446, 2013.

9. El-Quliti, S. A., Estimating the frequency, magnitude and recurrence of extreme earthquakes in medina area, Saudi Arabia, International Journal of Current Research, 8(04), 29952-29559, 2016.

10. Gautam, J. L., P. Chingtham, S. Baruah, R. P. Tiwari, Spatial and Temporal Distribution of Seismicity Parameters in Northeast India Constrained to Indo-Myanmar Region, Journal of Indian Society of Earthquake Science, 5, 32-45, 2018.

11. Gutenberg, B., C. F. Richter, Frequency of earthquakes in California, Bull Seismol Soc Am., 34, 185$188,1944$.

12. Jafari, M. A., Spatial distribution of seismicity parameters in the Persian Plateau, Earth Planets Space, 65, 863-869, 2013.

13. Kolathayar, S. and T. G. Sitharam, Characterization of regional seismic source zones in and around India, Seismol. Res. Lett., 83(1), 77-85, 2012.

14. Kolathayar, S., T. G. Sitharam, K. S. Vipin, Spatial variation of seismicity parameters across India and adjoining areas, Nat. Hazards, 60(3), 1365-1379, 2012.

15. Kayal, J. R., S. S. Arefiev, S. Baruah, R. Tatevossian, N. Gogoi, M. Sanjoum, J. L. Gautam, D. Hazarika, D. Borah, The 2009 Bhutan and Assam felt earthquakes (Mw 6.3 and 5.1) in Northeast Himalaya Region: the active fault. Geometrics Nat. Hazards and Risk, 1(3), 273-281, 2010.

16. Kayal, J. R., S. S. Arefiev, S. Baruah, D. Hazarika, N. Gogoi, J. L. Gautam, S. Baruah, C. Dorbath, R. Tatevossian, Large and great earthquakes in the Shillong plateau-Assam valley area of Northeast India region: pop-up and transverse tectonics, Tectonophysics, 532-535, 186-192, 2012.

17. Oldham, R. D., Report on the great earthquake of the 12th June 1897, Memoirs. Memoirs of the Geological Survey of India, 379, 1899.

18. Pacheco, J. F., C. H. Scholz, L. R. Sykes, Changes in frequency-size relationship from small to large earthquakes, Nature, 355, 71-73, 1992. 
19. Pandey, A. K., P. Chingtham, P. N. S, Roy, Homogeneous earthquake catalog for Northeast region of India using robust statistical approaches, Geomat. Natural Hazards and Risk, 8, 1-15, 2017.

20. Pandey, A. K., P. N. S, Roy, P. R. Baidya, A. K. Gupta, Estimation of Current seismic hazard using Nakamura technique for the northeast India, Journal of Natural Hazards, 93(2), 1013-1027, 2018.

21. Pandey, A. K., P. Chingtham, S.K. Prajapati, P. N. S, Roy, A. K. Gupta, Recent seismicity rate forecast for North East India: An approach based on rate state friction law, Journal of Asian Earth Sciences, 174, 167-176, 2019.

22. Raghukanth, S. T. G. Estimation of seismicity parameters for India, Seismol. Res. Lett., 81(2), 207$217,2010$.

23. Rydelek, P. A. and I. S. Sacks, Testing the completeness of earthquake catalogues and the hypothesis of self-similarity, Nature, 337(6204), 251-253, 1989.

24. Roy, S., U. Ghosh, S. Hazra, J. R. Kayal, Fractal dimension and b-value mapping in the AndamanSumatra subduction zone, Nat Hazards, 2010.

25. Shanker, D. and M. L. Sharma, Estimation of seismic hazard parameters for the Himalayas and its vicinity from complete data files, Pure Appl. Geophys., 152(2), 267-279, 1998.

26. Singh, C., P. M. Bhattacharya, R. K. Chadha, Seismicity in Koyna-Warna reservoir site in western India: fractal and b-value mapping, Bull Seismological Soc Am., 98, 476-482, 2008.

27. Singh, C., R. K. Chadha, Variations in the frequency_magnitude distribution with depth in the Koyna, Reservoir site, India, J. Asian Earth Sci., 39,331-334, 2010.

28. Singh, C., Spatial variation of seismic $b$-values across the NW Himalaya, Geomatics, Natural Hazards and Risk, 7(2), 522-530, 2016.

29. Srivastava, K., S. Rani, D. Srinagesh, A review of b-value imaging and fractal dimension studies in the Andaman Sumatra subduction, Nat Hazards, 77, 97-107, 2014.

30. Thingbaijam, K. K. S., S. K. Nath, A. Yadav, “Recent seismicity in northeast India and its adjoining region", J. Seismol., 12, 107-123, 2008.

31. Thingbaijam, K. K. S., P. Chingtham, S. K. Nath, Seismicity in the North-West Frontier Province at the Indian-Eurasian plate convergence, Seismol Res Lett., 80, 599-608, 2009.

32. Uhrhammer, R. A., Characteristics of northern and central California seismicity, Earthq. Notes, 57(1), 21, 1986.

33. Wiemer, S., A software package to analyze seismicity: ZMAP, Seismol. Res. Lett., 72(3), 373-382, 2001.

34. Wiemer, S. and M. Wyss, Mapping the frequency-magnitude distribution in asperities: an improved technique to calculate recurrence times? J Geophys Res, 102, 15115-15128, 1997.

35. Wiemer, S. and M. Wyss, Minimum magnitude of completeness in earthquake catalogues: Examples from Alaska, the western United States, and Japan, Bull. Seismol. Soc. Am., 90(4), 859-869, 2000.

36. Wiemer, S. and M. Wyss, Mapping spatial variability of the frequency-magnitude distribution of earthquakes, Adv. Geophys., 45, 259-302, 2002. 
37. Woessner, J. and S. Wiemer, Assessing the quality of earthquake catalogues: Estimating the magnitude of completeness and its uncertainty, Bull. Seismol. Soc. Am., 95(2), 684-698, 2005.

38. Yadav, R.B.S., P. Bormann, B. K. Rastogi, M. C. Das, S. Chopra, A homogeneous and complete earthquake catalog for Northeast India and the adjoining region, Seismol. Res. Lett., 80, 609-627, 2009.

\section{Figures}

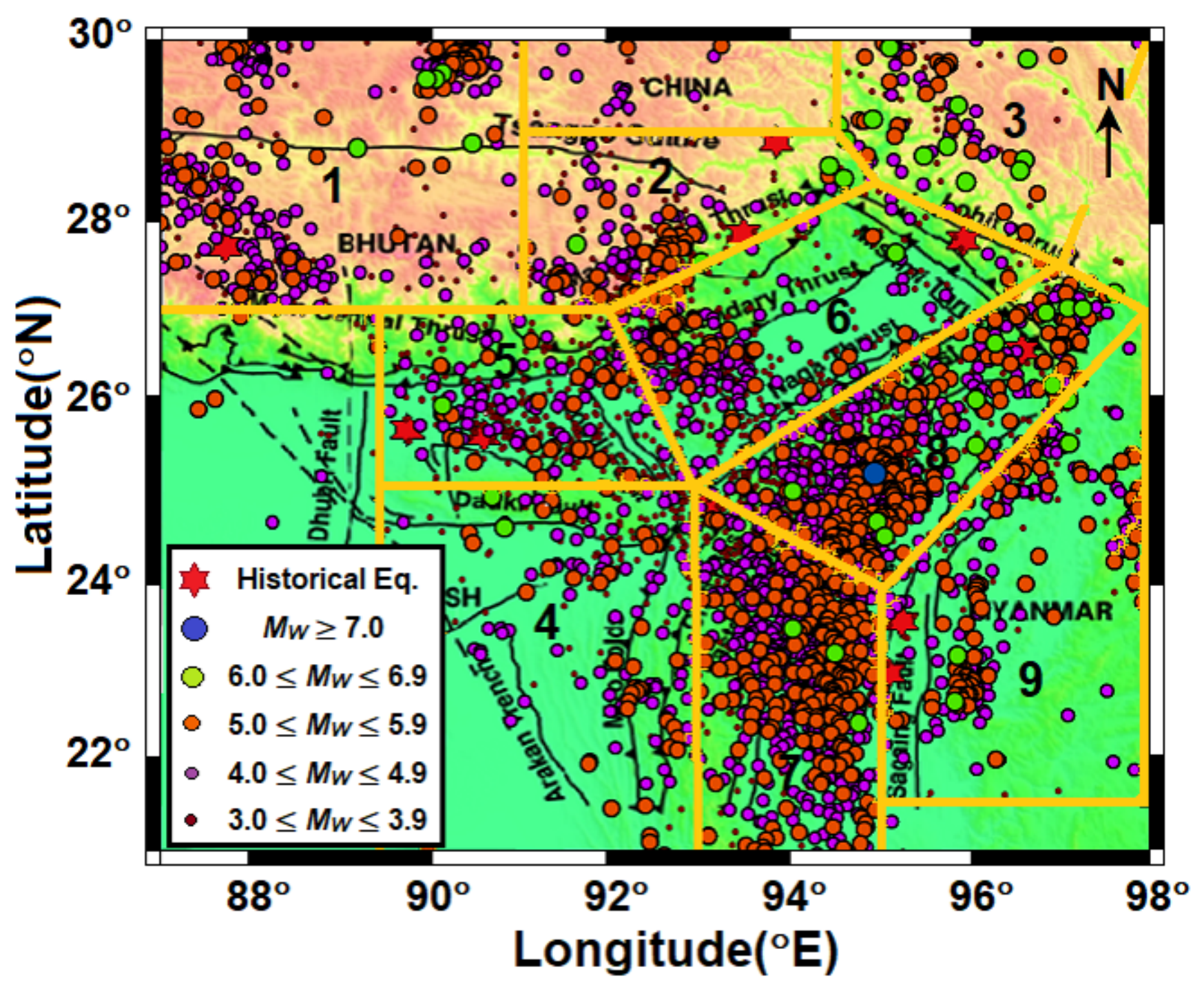

Figure 1

Seismotectonic map of Northeast India with decluster events $M W \geq 3.0$ covering the period from $1 \mathrm{st}$ January, 1976 to 30th June, 2020. Yellow lines indicated the seismogenic source zones based on seismicity, focal mechanism, and tectonic activity of earthquake. Nine seismogenic source zones are denoted by 1 to 9 . Note: The designations employed and the presentation of the material on this map do not imply the expression of any opinion whatsoever on the part of Research Square concerning the legal 
status of any country, territory, city or area or of its authorities, or concerning the delimitation of its frontiers or boundaries. This map has been provided by the authors.

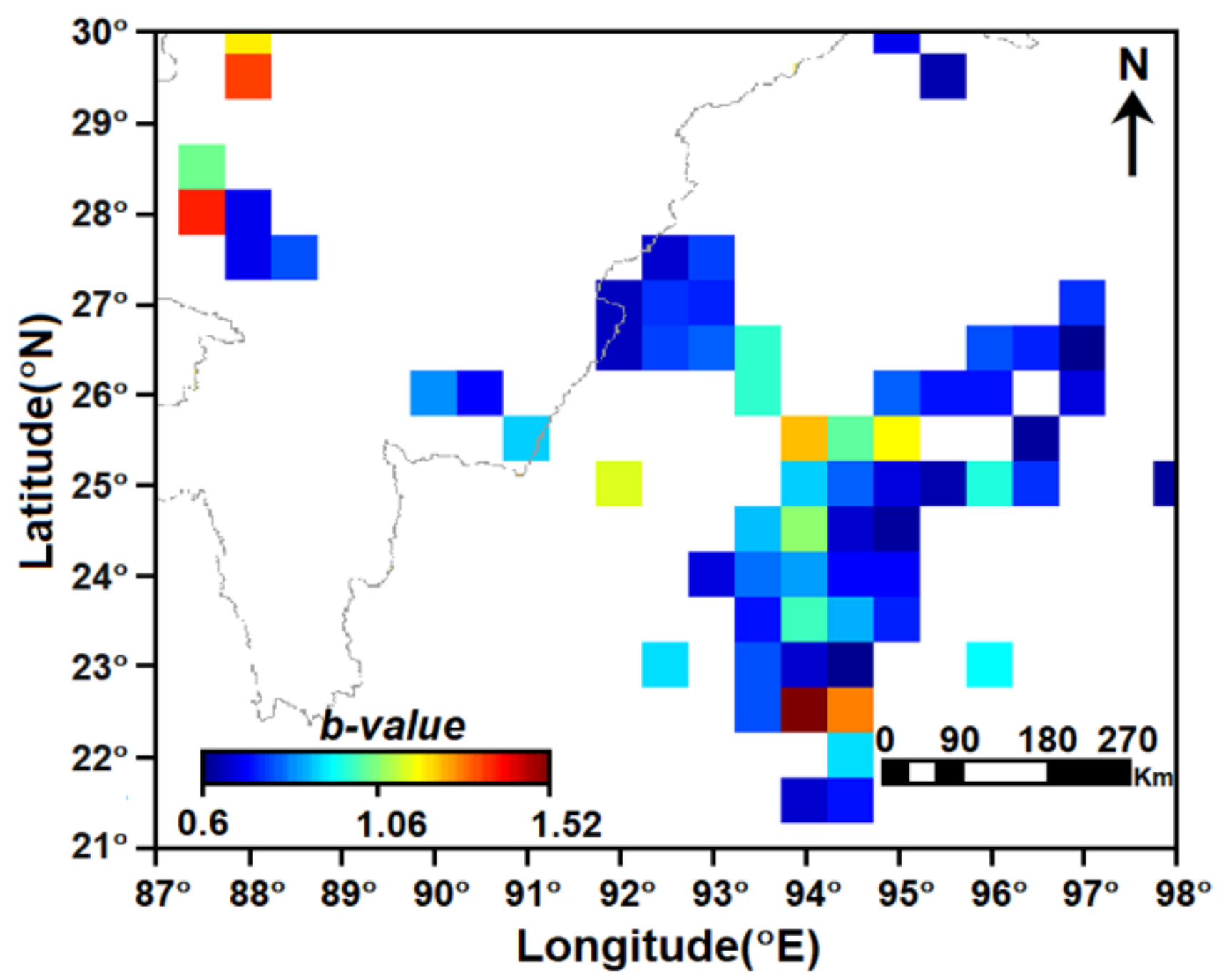

Figure 2

The spatial distribution of "b-value" from the declustered catalogue by using the Maximum-likelihood method from the period of 1st January, 1976 to 30th June, 2020 for Northeast India. 


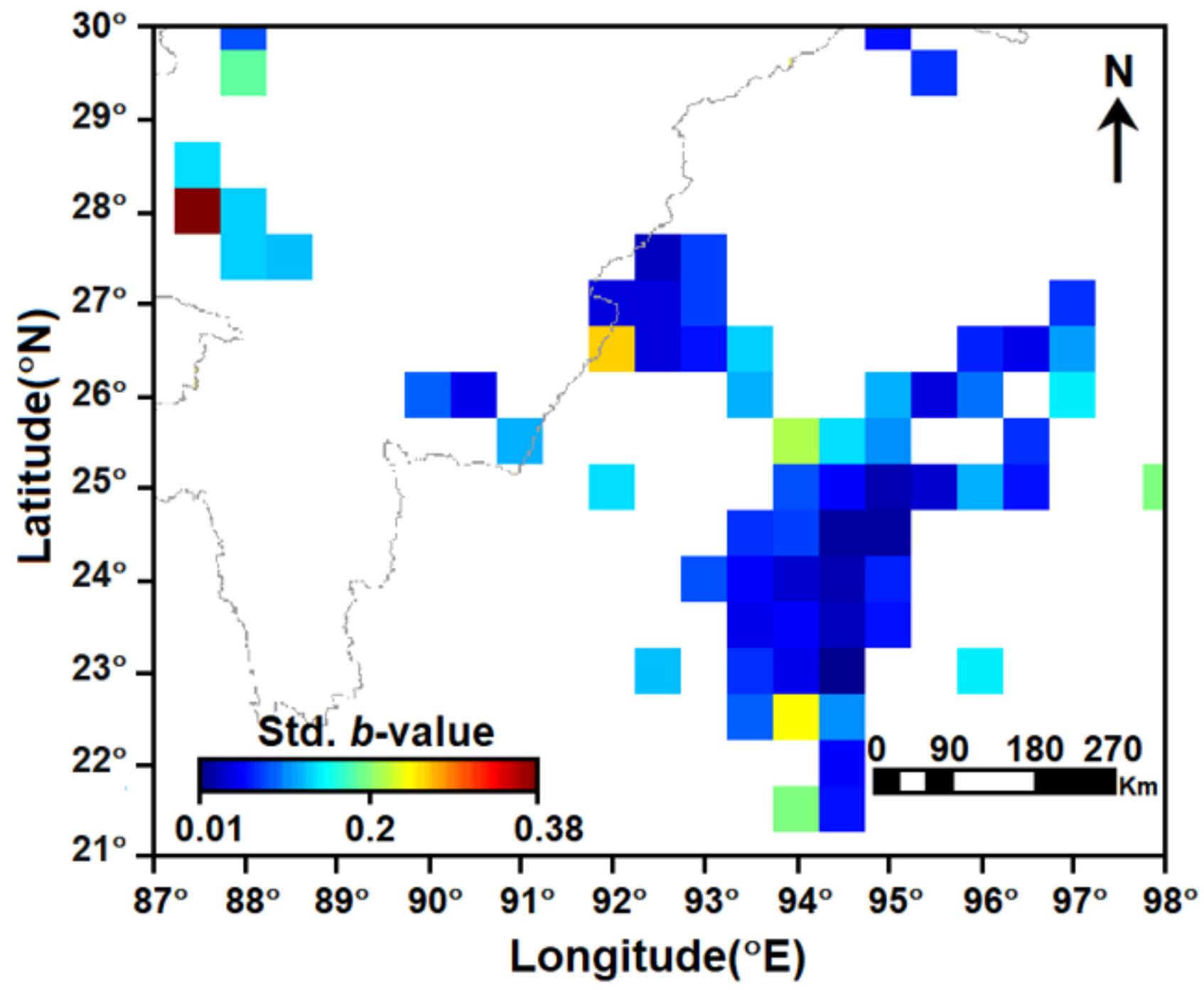

Figure 3

The spatial distribution of standard "b-value" from the declustered catalogue from the period of 1 st January, 1976 to 30th June, 2020 for Northeast India. 


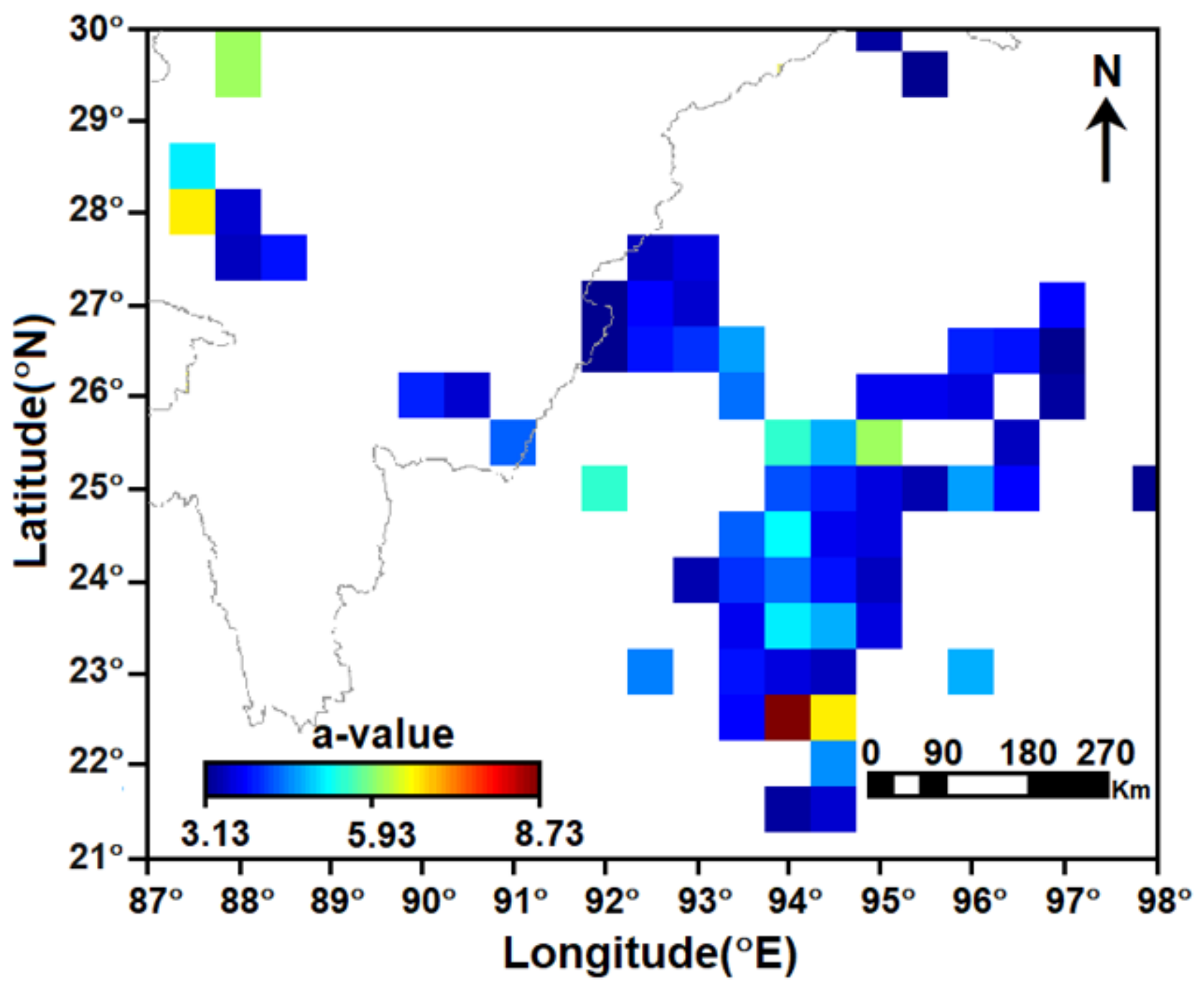

Figure 4

The spatial distribution of a-value from the declustered catalogue from the period of 1st January, 1976 to 30th June, 2020 for Northeast India. 


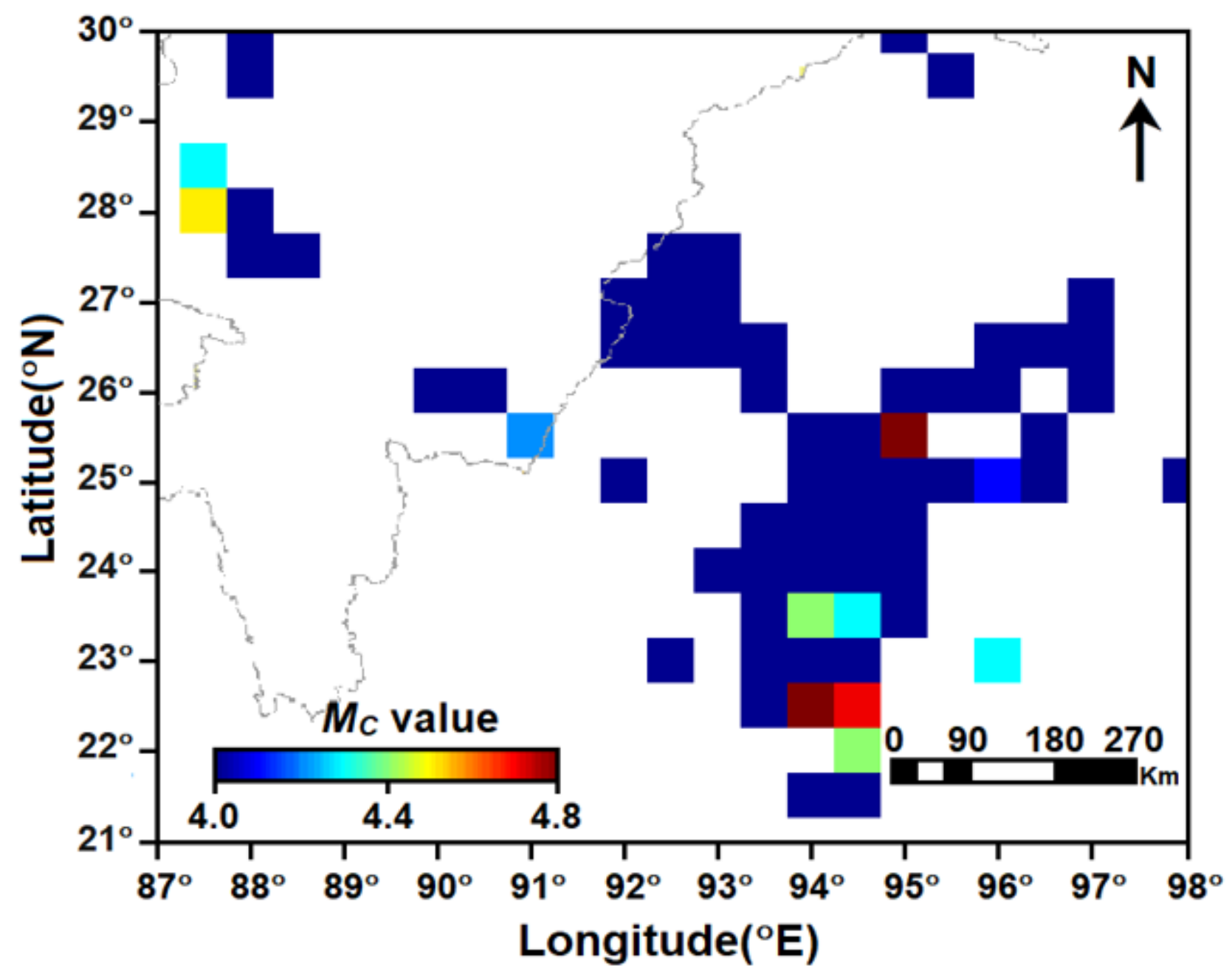

Figure 5

The spatial distribution of Magnitude of completeness, (MC) from the declustered catalogue from the period of 1st January, 1976 to 30th June, 2020 for Northeast India. 


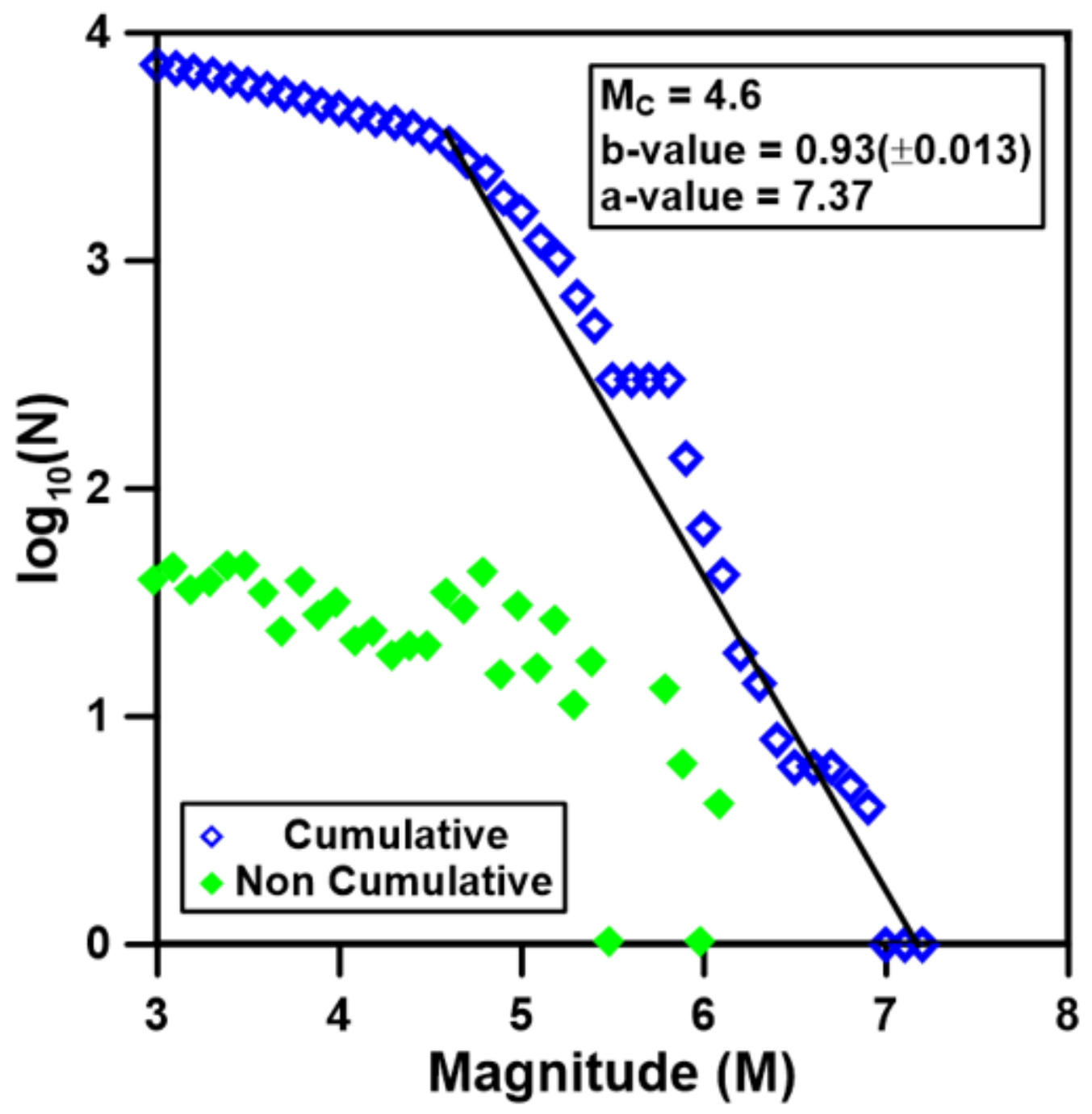

Figure 6

Frequency-magnitude distribution from the period of 1st January, 1976 to 30th June, 2020 for Northeast India. 


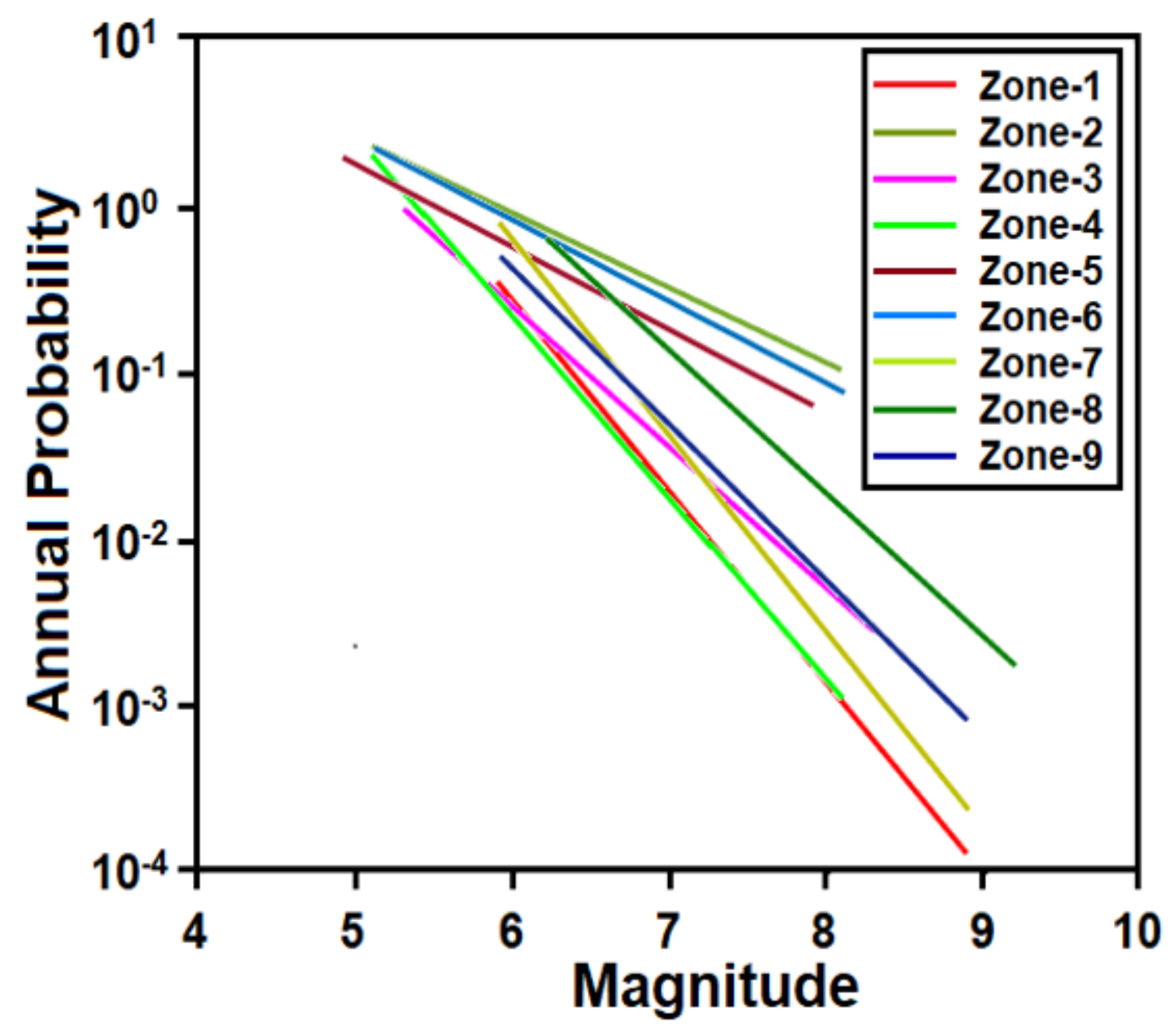

Figure 7

Annual Probability of occurrence of the earthquake $(\mathrm{MW}=3.0)$ for nine seismogenic source zones of Northeast India. 


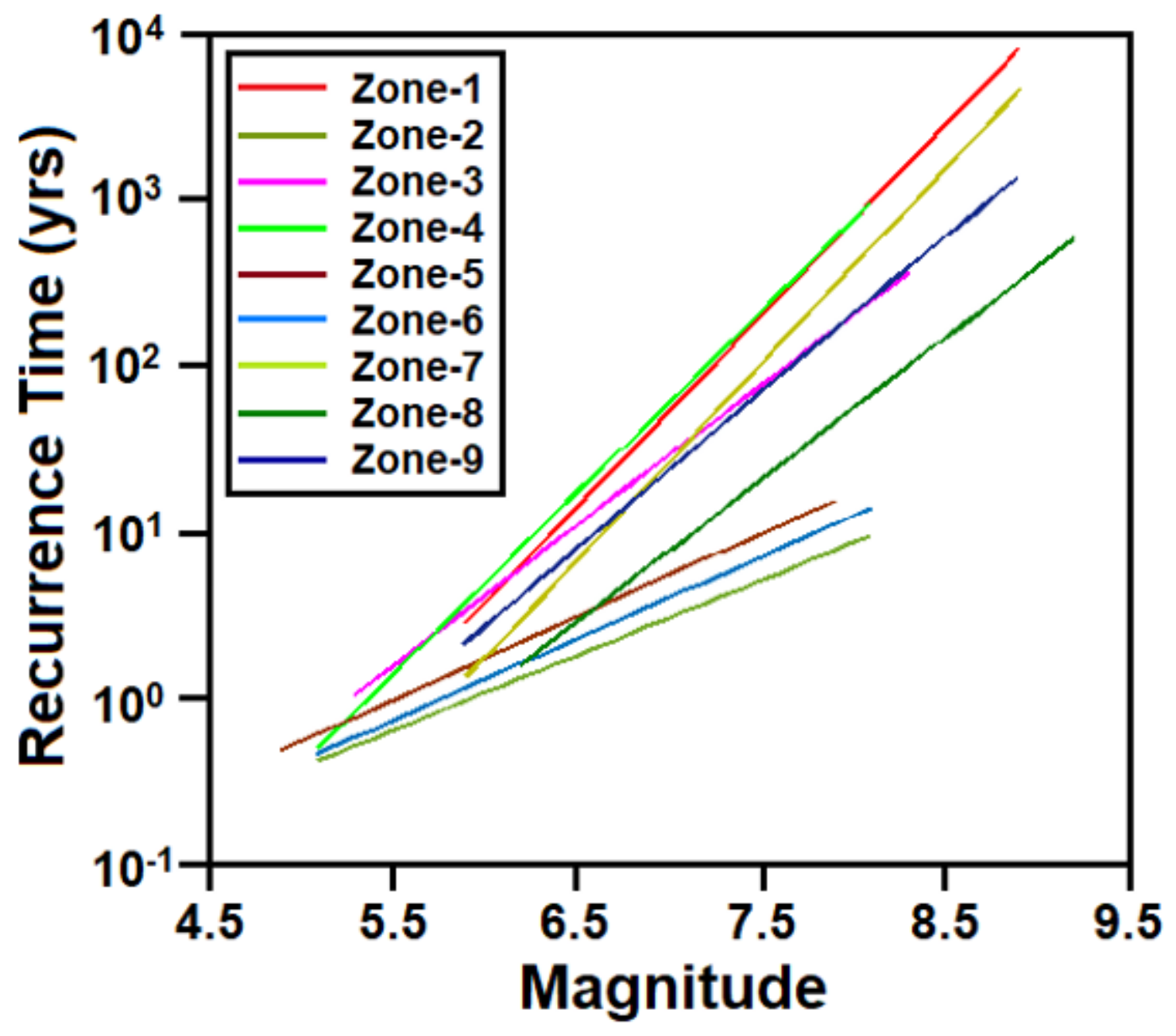

Figure 8

Return Period (yrs) of occurrence of the earthquake $(\mathrm{MW}=3.0)$ for nine seismogenic source zones of Northeast India. 